\title{
A new growth chart for preterm babies: Babson and Benda's chart updated with recent data and a new format
} Tanis R Fenton*

\author{
Address: Department of Community Health Sciences, Faculty of Medicine, University of Calgary, 3330 Hospital Drive NW, Calgary, Alberta, T2N \\ $4 \mathrm{~N} 1$, Canada \\ Email: Tanis R Fenton* - tanisfenton@shaw.ca \\ * Corresponding author
}

Published: 16 December 2003

BMC Pediatrics 2003, 3:13
Received: 10 June 2003

Accepted: 16 December 2003

This article is available from: http://www.biomedcentral.com/I47I-243I/3/I3

(C) 2003 Fenton; licensee BioMed Central Ltd. This is an Open Access article: verbatim copying and redistribution of this article are permitted in all media for any purpose, provided this notice is preserved along with the article's original URL.

\begin{abstract}
Background: The Babson and Benda 1976 "fetal-infant growth graph" for preterm infants is commonly used in neonatal intensive care. Its limits include the small sample size which provides low confidence in the extremes of the data, the 26 weeks start and the 500 gram graph increments. The purpose of this study was to develop an updated growth chart beginning at 22 weeks based on a meta-analysis of published reference studies.
\end{abstract}

Methods: The literature was searched from 1980 to 2002 for more recent data to complete the pre and post term sections of the chart. Data were selected from population studies with large sample sizes. Comparisons were made between the new chart and the Babson and Benda graph. To validate the growth chart the growth results from the National Institute of Child Health and Human Development Neonatal Research Network (NICHD) were superimposed on the new chart.

Results: The new data produced curves that generally followed patterns similar to the old growth graph. Mean differences between the curves of the two charts reached statistical significance after term. Babson's $10^{\text {th }}$ percentiles fell between the new data percentiles: the 5th to 17th for weight, the 5 th and 15 th for head circumference, and the 6 th and 16 th for length. The growth patterns of the NICHD infants deviated away from the curves of the chart in the first weeks after birth. When the infants reached an average weight of 2 kilograms, those with a birthweight in the range of 700 to 1000 grams had achieved greater than the $10^{\text {th }}$ percentile on average for head growth, but remained below the $3^{\text {rd }}$ percentile for weight and length.

Conclusion: The updated growth chart allows a comparison of an infant's growth first with the fetus as early as 22 weeks and then with the term infant to 10 weeks. Comparison of the size of the NICHD infants at a weight of 2 kilograms provides evidence that on average preterm infants are growth retarded with respect to weight and length while their head size has caught up to birth percentiles. As with all meta-analyses, the validity of this growth chart is limited by the heterogeneity of the data sources. Further validation is needed to illustrate the growth patterns of preterm infants to older ages. 


\section{Background}

Growth monitoring is a part of the medical and nutritional assessment of preterm infants. Growth charts provide the basis for this assessment by providing a comparison to a reference which allows for a visual picture of both the infant's achieved size and growth trajectory. Parents and health professionals like to know whether a preterm infant is able to maintain growth velocity or achieve catch-up in growth compared to the fetus and the term infant. Intrauterine growth charts allow this comparison for infants before term. Babson and Benda (Babson) [1] extended an intrauterine chart past term age by including a section based on the growth of infants born at term. They published this chart in 1976 which they referred to as a "fetal-infant growth graph".

The growth chart developed by Babson is still recommended for use in Neonatal Intensive Care Units [2,3]. In a recent survey of 118 neonatal health professionals, the growth chart used most frequently was that of Babson [1] (50\%), followed by that of Lubchenco, Hansman \&, Boyd [4] $(42 \%)$ and then by the one by Dancis [5] (18\%) (unpublished data).

Although commonly used, Babson's growth chart has limitations. The $\mathrm{X}$ axis begins at 26 weeks of gestation thus limiting its usefulness to plot younger preterm infants from birth. The $\mathrm{Y}$ axis is made in 500 gram increments which make precise plotting difficult. The sample size of the data behind Babson's chart was small. There were only 45 infants in their sample that were 30 weeks or younger [6]. The data was 15 years old at the time of publication and is now 40 years old.

The purpose of this project was to prepare an updated fetal-infant Babson-type growth chart for use in neonatal intensive care units. This chart will allow a comparison for preterm infants as young as 22 weeks of gestation, first with intrauterine and then with post term references.

\section{Methods}

\section{Literature review and selection}

A search of the literature was conducted on three databases (Pub Med, the Cochrane Library, EMBASE from 1980 to June 2002) using the subject headings: infant, (premature, very low birthweight), anthropometry, growth, birthweight, head, cephalometry, gestational age, newborn, and reference values. Articles selected included surveys of intrauterine and post term growth. Reference lists of relevant articles were searched.

To improve on the Babson graph, two types of data were needed: infant size measured at the time of birth for the intrauterine section and term infant measurements for the post-term section. Population studies with large sample sizes were preferred to improve generalizability. The World Health Organization has recommended that gestational age of infants be described as completed weeks [7], so data stated in this manner were favored. Numerical data were preferred over graphic depiction to ensure accuracy.

\section{Intrauterine data}

Three recent large population based [8-10] surveys of birthweight for various gestational ages were identified in the literature search. These studies used statistical methods to delete implausible birth weight-gestational age combinations and then smoothed the birth weight curves across gestational age categories. The Canadian study by Kramer et al [8] was selected for the intrauterine weight section since their methods produced the most plausible distribution of birth weights particularly for 28 through 36 weeks. For example, the $50^{\text {th }}$ and $90^{\text {th }}$ percentiles for 32 weeks in Alexander's corrected data were 2.2 and 3.2 kilograms $(\mathrm{kg})$ respectively. The $50^{\text {th }}$ and $90^{\text {th }}$ percentiles for 32 weeks in Kramer's corrected data were the more plausible 1.9 and $2.3 \mathrm{~kg}$, respectively. Kramer et al used a statistical method to correct for misclassification of term infants incorrectly labeled as preterm. Table 1 lists details regarding the data sources used.

Two population based studies that met the a priori criteria included head circumference and length, one from Sweden by Niklasson et al [11] and one from Australia by Beeby et al [12]. A limitation with the Swedish survey was that it did not include data prior to 29 weeks, however both were used since the Swedish study was based on a large sample.

To develop the head circumference and length curves, the numerical data from Niklasson [11] and Beeby [12] were averaged together using a weighted average based on total sample size. Ideally the combining of these two data sources would have been done with the raw data to create one distribution for each gestational age, however this was not possible from the published data. Since the sample sizes were very different $(380,000$ vs 30,000$)$, the resulting weighted averages were predominantly influenced by the Swedish data. Therefore the head circumference and length curves are only Australian data prior to 30 weeks and then predominately Swedish data after 30 weeks.

There was remarkable consistency between the head and length results from the Australian and Swedish studies. Between 31 and 33 weeks; the differences were less than 0.3 centimeter $(\mathrm{cm})$ for $50^{\text {th }}$ percentiles and $0.4 \mathrm{~cm}$ for the $10^{\text {th }}$ and $90^{\text {th }}$ percentile curves. The magnitudes of the differences were greater for data at 29 weeks and greater than 36 weeks which may to be due to the way the Swedish 
Table I: Details of the Data Sources

\begin{tabular}{|c|c|c|c|c|}
\hline & Kramer [8] & Niklasson [I I] & Beeby [12] & CDC [13] \\
\hline Data used & Birthweight $\leq 40$ weeks & Head and length measures $\leq 40$ weeks & $\begin{array}{l}\text { Head and length measures } \leq 40 \\
\text { weeks }\end{array}$ & $\begin{array}{l}\text { Weight, head and length } \\
\text { measures after term }\end{array}$ \\
\hline Sample size $(n)$ & 676,605 & 376,000 & $\begin{array}{l}\text { Head circumference: } 29090 \text { and } \\
\text { length: } 26973\end{array}$ & $\begin{array}{l}\text { Birth data :weight: } 82 \text { million, } \\
\text { length: } 900,000 \text {, head } \\
\text { circumference: } 400 \text {. First year } \\
\text { of life: } 2200 \text { to } 38,000 \text { infants. }\end{array}$ \\
\hline $\mathrm{n}<30$ weeks & 4101 & 0 & 274 & N/A \\
\hline $\begin{array}{l}\text { Gestational age range of } \\
\text { study }\end{array}$ & 22 to 43 weeks & 28.5 to 42.5 weeks & 22 to 43 weeks & Post term \\
\hline Inclusion criteria & All births & "Healthy" newborn infants & Singleton livebirths & NHANES surveys \\
\hline Exclusion criteria & $\begin{array}{l}\text { Ontario (province) was } \\
\text { excluded due to problems with } \\
\text { data quality. }\end{array}$ & $\begin{array}{l}\text { Stillbirths, twins, complications during } \\
\text { pregnancy with potential effects on } \\
\text { fetal growth and significant } \\
\text { malformations }\end{array}$ & Multiple births & $\begin{array}{l}\text { Infants with birthweights < } \\
\text { I } 500 \text { grams }\end{array}$ \\
\hline Dates & 1994 to 1996 & 1977 to 81 & 1982 to 1995 & Primarily 1963 to 1994 \\
\hline $\begin{array}{l}\text { Completed gestational } \\
\text { weeks }\end{array}$ & yes & yes & yes & $\mathrm{N} / \mathrm{A}$ \\
\hline $\begin{array}{l}\text { Method to assess } \\
\text { gestational age }\end{array}$ & $\begin{array}{l}\text { "early ultrasound has } \\
\text { increasingly been the basis for } \\
\text { gestational age assessments in } \\
\text { recent years" }\end{array}$ & $\begin{array}{l}\text { Last menstrual period was used when } \\
\text { it was in agreement }(+/-2 \text { weeks) with } \\
\text { the obstetric assessment. If not, the } \\
\text { latter was used. When either estimate } \\
\text { was missing the gestational age was } \\
\text { considered unknown. }\end{array}$ & $\begin{array}{l}\text { In the majority of cases the } \\
\text { gestational age was based on first } \\
\text { trimester ultrasound, or when early } \\
\text { ultrasound was not available, last } \\
\text { menstrual period dates were used. } \\
\text { In }<\text { I\% of cases, the Ballard } \\
\text { assessment was used when neither } \\
\text { dates nor ultrasound were available. }\end{array}$ & N/A \\
\hline Outliers & $\begin{array}{l}\text { Assumed a log normal } \\
\text { distribution of birthweight at } \\
\text { each gestational age and } \\
\text { compared the probabilities of } \\
\text { accurate versus misclassification } \\
\text { of infant's gestational age. }\end{array}$ & & $\begin{array}{l}\text { The mother's medical record was } \\
\text { examined and following verification } \\
\text { of the gestational age and other data, } \\
\text { outliers were either accepted as real } \\
\text { or corrected. }\end{array}$ & $\begin{array}{l}\text { Curves were smoothed with } \\
\text { a variety of parametric and } \\
\text { non-parametric procedures }\end{array}$ \\
\hline
\end{tabular}

data was reported. These data were expressed as a third degree polynomial function, so their curves were curved downward at both ends. At the ends of the curves the differences increased to $0.4 \mathrm{~cm}$ at both ends of the curve for head circumference and to $0.8 \mathrm{~cm}$ (29 weeks) and $1.0 \mathrm{~cm}$ (40 weeks) for length. (This problem was dealt with under Smoothing of the Curves.) The consistency in the mid sections of the curves provides confidence regarding the combining of the results from these two studies.

\section{Post 40 week data}

In selecting the term infant data for the post 40 weeks section of the fetal-infant chart the Center for Disease Control (CDC) [13-15] data met the a priori criteria of being based on large samples and having a numerical version available. The CDC Growth Data is a compilation of growth surveys of American multiracial-ethnic breast and formula fed infants born between 1963 and 1994 [13]. The data are mostly cross sectional, but include some longitudinal measures.

\section{Chart development}

The data for both genders were averaged together for the $3^{\text {rd }}, 10^{\text {th }}, 50^{\text {th }}, 90^{\text {th }}$ and $97^{\text {th }}$ percentiles to create one growth chart. Separate gender charts were not produced since the gender differences were considered not important enough to warrant separate charts. The sample sizes for the birthweight data are very large, so significant differ- ences between the genders could be seen for most ages even when the differences were small and of minor practical importance. Specifically, the differences between the male and female weights were statistically significant at all ages above 23 weeks for the $50^{\text {th }}$ percentile (beginning with a difference of 32 grams) and above 24 weeks for the $3^{\text {rd }}$ percentile (beginning with a difference of 44 grams). None of the head and length or the CDC data were reported in a manner that permitted a statistical comparison by gender.

The largest differences between the genders were confined to late gestation and after term. Along the $3^{\text {rd }}$ percentile, there was only one weight difference between the genders that was greater than 100 grams (40 weeks) and none of the head differences were greater than $0.4 \mathrm{~cm}$. The differences between the genders along the $10^{\text {th }}$ percentile were limited to greater than 36 weeks for weight differences greater than 100 grams and only 1 head difference was greater than $0.6 \mathrm{~cm}$. Along the $50^{\text {th }}$ percentile the only differences between the genders for weight more than 100 grams were greater than 35 weeks and the only head differences greater than $0.4 \mathrm{~cm}$ were after term. For each of these three percentiles, only 1 length measure was greater than $1 \mathrm{~cm}$ and all of these were after term.

A large-scale grid was used to aid accuracy of plotting. The increments were 100 grams for weight, one $\mathrm{cm}$ for head 
circumference and length, and one-week intervals for time. The chart was extended to 50 weeks since the majority of preterm infants are discharged home by this age. Spaces were made at the bottom of the chart to note the date of measurements. The 3rd, 10th, 50th, 90th and 97th percentile curves for weight, head circumference and length were plotted on the grid. There were disjunctions between the data sets at 40 weeks. For example, the CDC $50^{\text {th }}$ percentile for weight was $2 \%$ lower than the Kramer value, while the $3^{\text {rd }}$ percentile was $14 \%$ lower. The disjunctions between the pre and post-term sections are likely due to artifacts of the original data sets and the processing methods.

\section{Smoothing of curves}

To produce a working chart, the disjunctions between the pre and post term sections needed to be smoothed. It was difficult to merge the pre- and post-term data sets at their boundaries. The goal of the smoothing was to produce a bridge between the pre-term and the post-term curves without the typical deceleration seen in intrauterine curves just before term. Initial approaches to numerically smooth the boundary produced obvious undesirable results. Therefore manual methods were used to smooth the disjunction from the deceleration point of the preterm curves to a point prior to the first measurement after term (at 2 months).

For weight the smoothing was done between 36 and 46 weeks. (Figure 1) The $50^{\text {th }}$ percentile needed the least modifying since both the Kramer and CDC weights at term were approximately $3.5 \mathrm{~kg}$. The $3 \mathrm{rd}$ percentile required smoothing up to 49 weeks. The smoothing for head circumference and length was continued back to 22 weeks to level the disjunction between the two data sources at 29 weeks. All of the curves had merged with the CDC curves prior to 50 weeks.

The final curves (Figure 2) were illustrated with different graphic styles to identify the different percentiles.

\section{Comparisons with the Babson chart}

Three comparisons were made between Babson's chart and the new data. First, a graphical comparison was prepared of Babson's mean, 3rd and $97^{\text {th }}$ percentiles superimposed on the new raw data (Figure 3). Second, means were compared between Babson's and the raw data based on the assumption that the data was not skewed, and therefore the $50^{\text {th }}$ percentiles were equal to the mean. This comparison was done using t-test at 28, 30, 32, 36, 40 weeks and 1.5 and 2.5 months. Standard deviations were estimated using a least squares fit of the percentiles to the normal curve. It was not possible to test for differences prior to 28 weeks since Babson did not include percentile curves until 28 weeks. A probability of $\mathrm{p}<0.05$ was con-

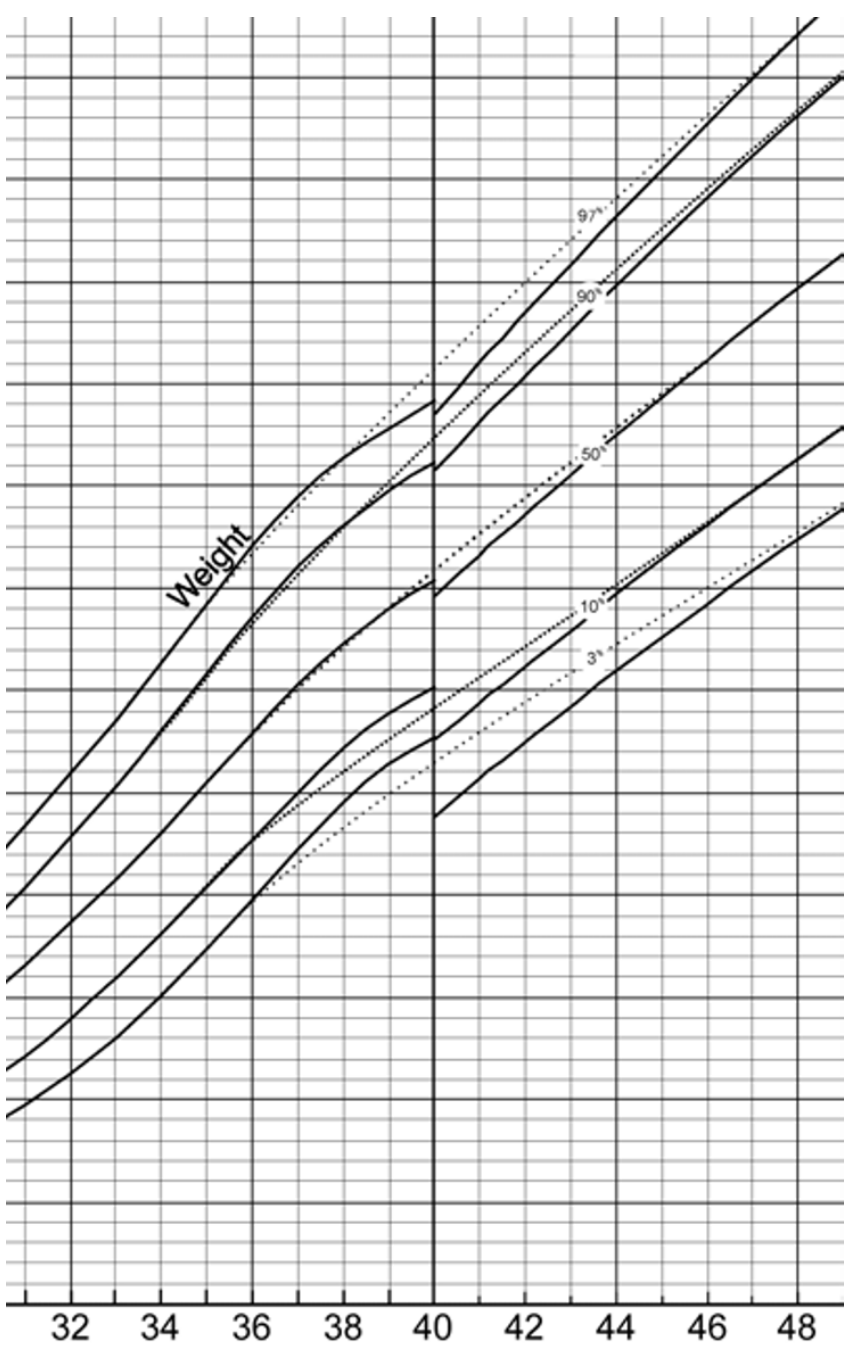

Figure I

Illustration of smoothed curves superimposed on the raw data curves. Solid curves are from the original data, dotted curves are the smoothed and final version.

sidered statistically significant and adjustment was made for multiple comparisons using the Bonferroni method.

The 10th percentile is a frequent cut point for assessment of size for age. The third comparison was a calculation of the percent of new chart values below Babson's $10^{\text {th }}$ percentile. This was done by first calculating Babson's $10^{\text {th }}$ percentile using the standard deviation estimate. Then $\mathrm{z}$ scores were calculated for Babson's $10^{\text {th }}$ percentile compared to the new distributions and an estimate was made of the percent of new data below Babson's $10^{\text {th }}$ percentile. This comparison was done at 28, 30, 32, 36 and 40 weeks and at 1 and 2 months. 


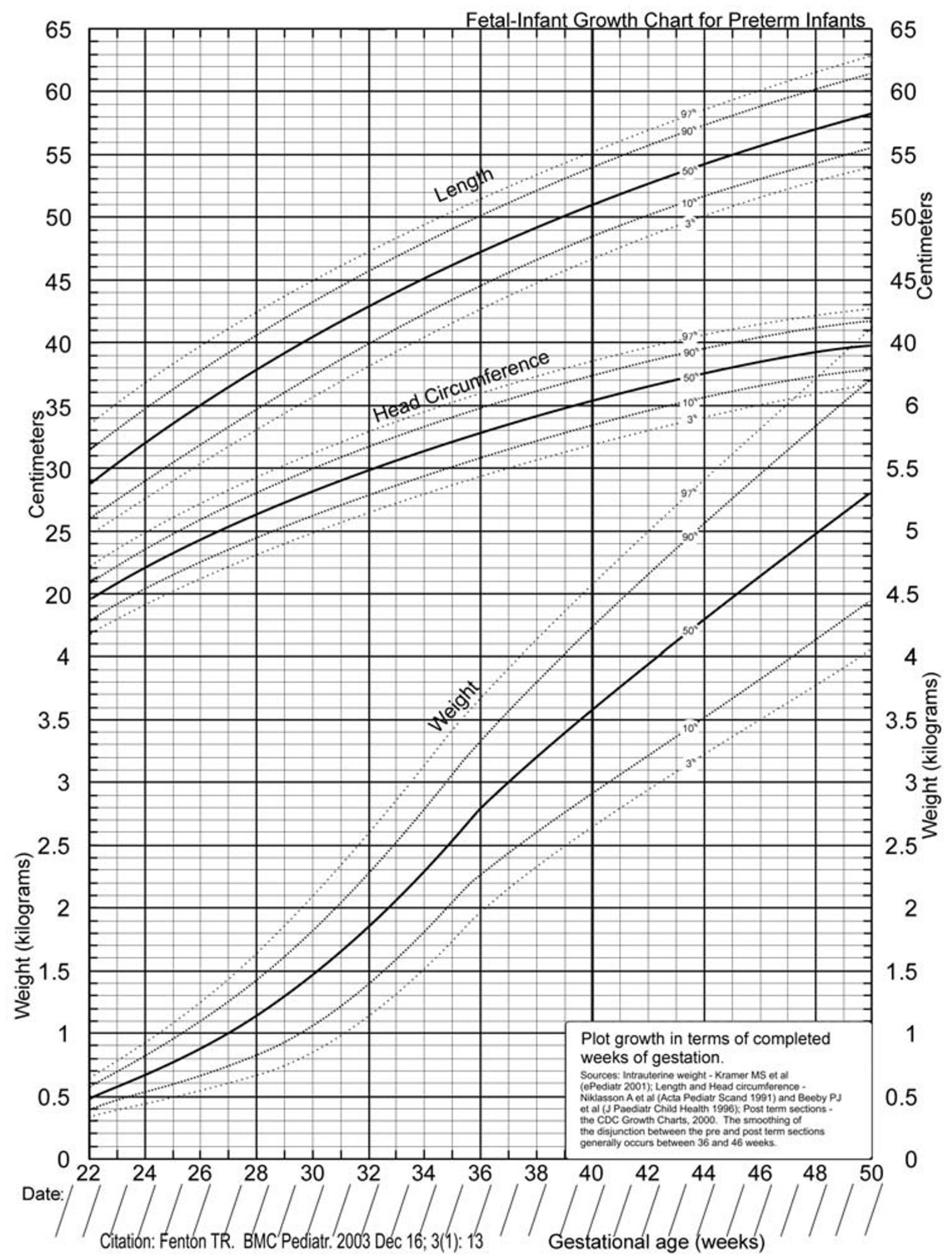

Figure 2

A new fetal-infant growth chart for preterm infants developed through a meta-analysis of published reference studies. 


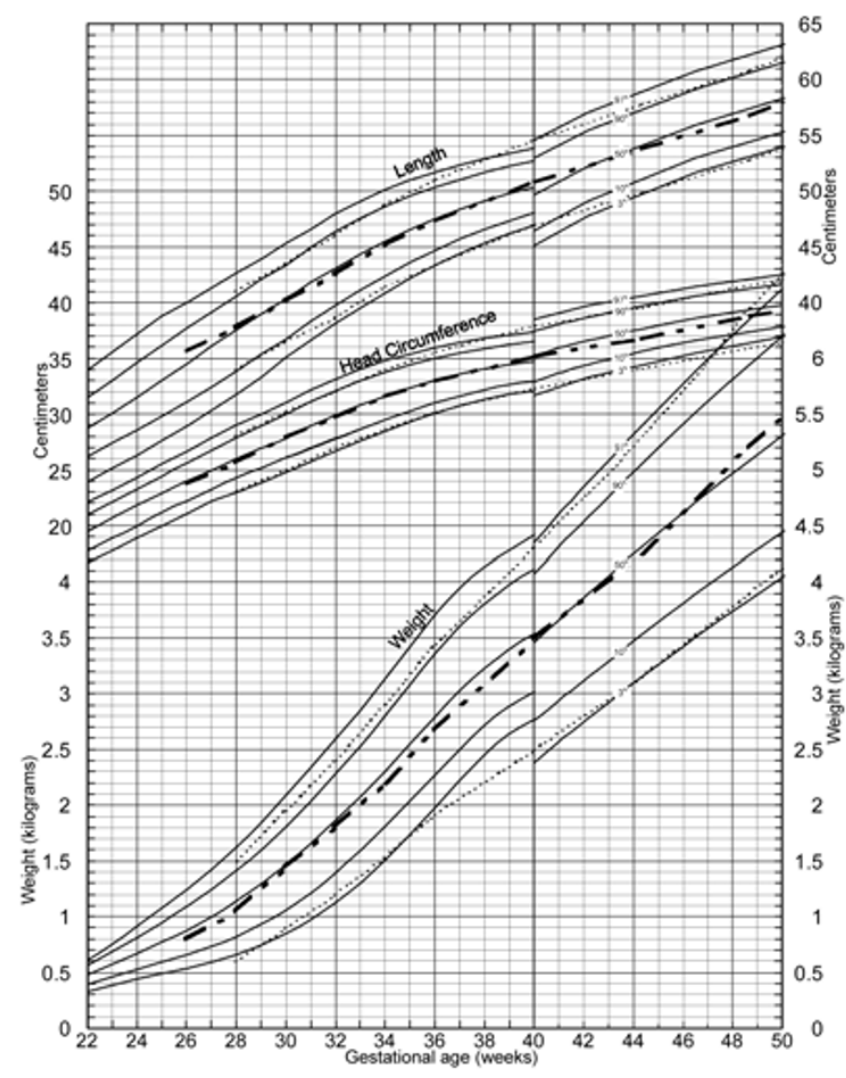

Figure 3

The dotted curves are Babson and Benda's 1976 fetal-infant growth curves superimposed on the raw data curves.

\section{How does the growth of preterm infants appear on the chart?}

The data from the large multicenter cohort study done by the National Institute of Child Health and Human Development Neonatal Research Network (NICHD) [16] were superimposed on the new growth chart (Figure 4). This study documented the growth patterns of 1660 very low birthweight infants born in 1994 and 1995. Infants with anomalies and those that did not survive were excluded from the study, but those with a variety of morbidities were included. For this comparison, the growth trends of the infants of average birthweights 550, 750, 950 and 1450 were used.

\section{Results}

\section{Comparisons with the Babson chart}

The graphical comparison of Babson's mean, 3rd and 97th percentiles [1] superimposed on the new raw data showed similar values along the $50^{\text {th }}$ percentile (Figure 3 ) with greater differences for the $3^{\text {rd }}$ and $97^{\text {th }}$ percentiles.

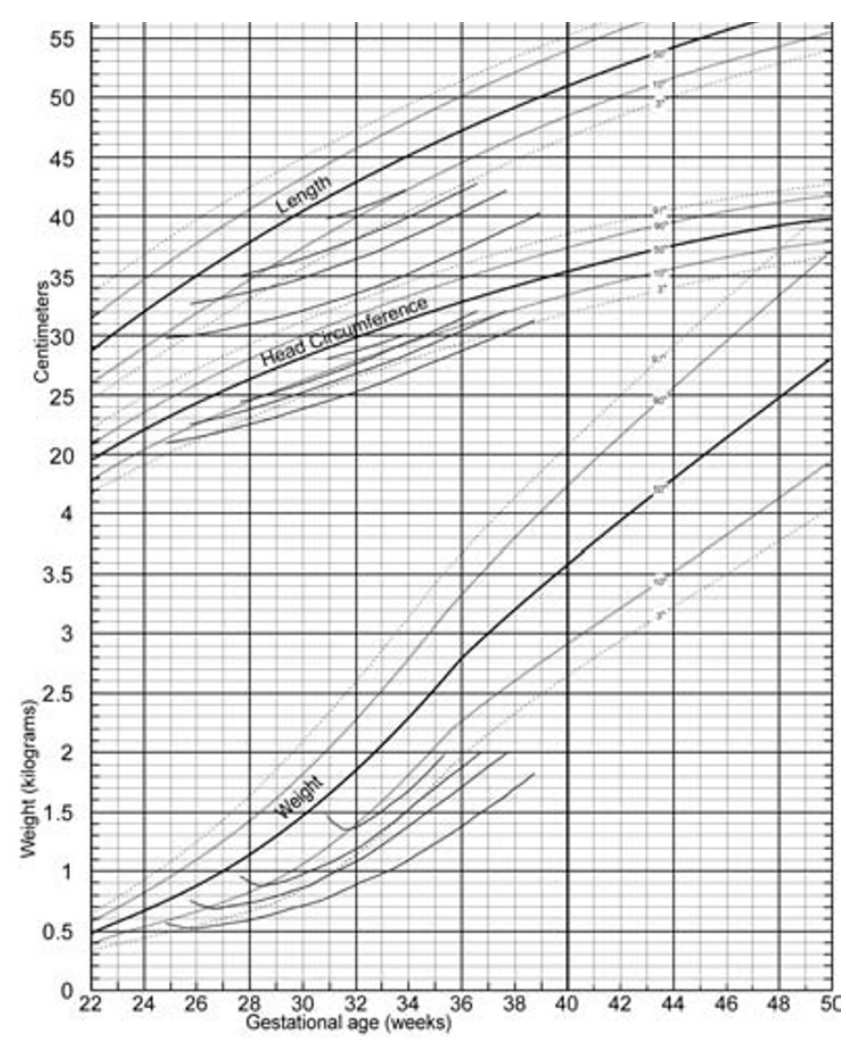

Figure 4

The postnatal growth data of 4 of the infant cohorts from the National Institute of Child Health and Human Development Neonatal Research Network superimposed on the new chart.

When the means of Babson's and the new data were compared, head circumference and length measures were significantly different $(\mathrm{p}<0.00005)$ after term. The small numbers in the sample used by Babson [6] before term limited the power of the statistical comparison to find differences for the younger ages. The largest numerical differences in mean weight between the two sources were at 36 weeks where the new data was 120 grams higher and at 2.5 months where the new data was 143 grams lower. The largest differences in means for head circumference and length were 1.0 centimetre at 1.5 months and $1.2 \mathrm{~cm}$ at 26 weeks, respectively. The largest discrepancies for all 3 parameters were at the $97^{\text {th }}$ percentile, with differences for weight of 260 grams at 36 weeks, for head circumference of $1.1 \mathrm{~cm}$ at 32 weeks and for length of $1.8 \mathrm{~cm}$ at both 30 and 32 weeks.

The percent of values below Babson's $10^{\text {th }}$ percentile ranged from the 5 th to 17 th for weight, the 5 th and 15 th 
for head circumference, and the 6th and 16th for length (data not shown).

\section{How does the growth of preterm infants appear on the chart?}

The growth curves from the NICHD for weight, length and head circumference showed clear deviations away from the intrauterine curves in the first weeks after birth. (Figure 4) The subsequent growth in weight of the infants with birthweights less than 1 kilogram was less than the late intrauterine rate but steeper than the post term slope. When the infants reached an average weight of 2 kilograms, all of the average weight growth curves were below the $10^{\text {th }}$ percentile, and the smaller three groups remained below the $3^{\text {rd }}$ percentile. The average growth of head circumference recovered the original birth percentiles except for the smallest group. Only the smallest group's average head size remained below the $10^{\text {th }}$ percentile. The average growth in length also recovered from the post birth deceleration but like weight, only the largest group had an average size above the $3^{\text {rd }}$ percentile.

\section{Discussion}

This new fetal-infant chart is an updated Babson-type growth chart for use in neonatal intensive care units. This chart will allow a comparison for preterm infants as young as 22 weeks of gestation first with intrauterine and then with post term references and it can replace the one developed by Babson [1] which has been used in neonatal intensive care for over 25 years. The $10^{\text {th }}$ percentile of this chart is accurate to the source data prior to 36 weeks; therefore it could be used for the assessment of size for gestational age for infants smaller than 2 kilograms.

This meta-analysis does not represent the actual growth of preterm infants for three reasons. First, the initial parts of the curves are based on the size of fetuses at birth, which do not show the change in weight that occurs after birth. This is followed by curves based on the growth of term infants who have not had the growth depressing effect of prematurity [17]. Another approach for monitoring growth of preterm infants using growth charts is to use a longitudinal postnatal growth chart. These growth charts show the pattern of initial weight loss after birth followed by subsequent growth of a sample of preterm infants. Examples include those by Dancis et al [5], Wright et al [18], and those developed by the Infant Health Development Program [19], and by the NICHD [16]. These longitudinal charts have the advantage of using samples of very low birth weight infants as the growth reference and showing the actual growth pattern of preterm infants. Their disadvantage is that they are not based on the growth standard for preterm infants, that is, on fetal growth [20,21]. Therefore they do not show an infant's growth velocity or catch-up in growth relative to the fetus or the term infant. Further, the curves on a longitudinal growth chart are highly influenced by the medical and nutritional care of the sample infants; growth patterns may change with innovations in medical and nutritional care [22]. The use of both fetal-infant and longitudinal charts together provide a more accurate assessment of growth of preterm infants [22].

Second, the validity of a meta-analysis is affected by methodological quality of the individual studies and the extent of heterogeneity in the studies and their results. Data from different studies were combined to prepare the graphs. It would have been preferable if all the data could have been obtained from one study with uniform methodology. The a priori criteria did limit the studies to those that were population based, had large sample sizes, and recorded gestational age in completed weeks. The studies used were all from developed countries where the majority of women are well nourished and the three studies used for the preterm section have publicly funded universal health care. The studies have slight differences in the inclusion and exclusion criteria (Table 1) which could have influenced their results. The most notable differences between the studies were the exclusion of multiple births from the Swedish and Australian surveys and the statistical adjustment of the Canadian survey data. There is evidence that the birthweight of infants from multiple gestations are reduced relative to the weight of singletons after 28 to 30 weeks of gestation [23]. The consistency of the results of the two sources of head circumference and length data was remarkable, which suggests that the differences between these two studies were not substantial.

Could a secular trend make the combining of the data invalid? There has been a slight trend towards an increase in birthweight of term infants in the United States and in Canada of 1 to 3 grams per year on average over the time frame that the data were collected [24,25]. No trends are apparent among infants of lower gestational ages [24,25]. Regarding head and length size, there is some evidence of small increases over this time period [26]. Since these differences are slight, their influence on the data is not likely of clinical significance.

Third, the smoothing that was applied to bridge the pre and post term curves may or may not be a valid estimate of the growth of preterm infants. Further validation studies will determine the soundness of the smoothed disjunction between the data sets. The ideal validation study would compare the growth of a population of healthy preterm infants followed prospectively from birth though 50 weeks post-conceptual age. Healthy infants should be used to decrease the chance of bias due to illness of prematurity, however it would be useful to also document the growth patterns of unwell infants on this growth chart. 
The superimposed NICHD growth curves (Figure 4) represent a mixed group of infants, some without complications and others with morbidities, and with varying size for gestational age [16]. When the infants from this study approached the average weight of 2 kilograms those infants with a birthweight in the range of 700 to 1000 grams on average achieved the $10^{\text {th }}$ percentile for head growth, but remained below the $3^{\text {rd }}$ percentile for weight and length.

This finding is similar to that seen in previous studies of the growth of preterm infants on this type of growth chart $[16,17,27]$. The growth of most preterm infants plotted on this type of chart track lower curves or below the curves because of the initial weight loss after birth and the extended time required for catch up growth to occur $[17,28]$. There appears to be a priority among preterm infants for growth of head circumference over weight and length growth [27] and of weight over length growth $[17,27]$. Catch up growth of preterm infants is a long term process and small preterm infants are growth retarded during the first years of life [17]. The curves of the fetalinfant growth chart provide a backdrop against which an infant's growth trajectory can be plotted.

There were agreements and differences between this newer data with that of Babson. The agreements suggest that the Babson curves had fairly accurate depictions of infant size which may account for the continued popularity of this chart. The differences may reflect the small sample sizes of the early chart and the use of only maternal dates for the gestational age [6]. The larger sample sizes used here may provide better confidence in the extreme percentiles [29].

The fetal-infant chart encourages the use of age that is adjusted for prematurity after 40 weeks. Once an infant surpasses 50 weeks, the regular CDC growth charts could be used, with continued adjustment for prematurity. Some authors have suggested that age be adjusted for preterm infants to at least 3 years [30], or even up to 7 years [31].

The data behind the new chart are predominantly cross sectional. Data of this type can be criticized since they are based on attained size of individuals and not on actual growth patterns [15]. However, cross sectional growth charts, such as the CDC Growth Charts, are useful for assessment of growth over time [15].

The selection of the CDC data for the post 40 week section may not be ideal since the database excluded preterm infants with a birth weight less than $1.5 \mathrm{~kg}$. These infants grow differently than those of higher birthweight and this exclusion make the CDC charts more like a growth stand- ard [14]. However, this data of mostly normal birthweight infants have some advantages in that they are intuitively understood and their use aids the assessment of whether catch-up growth is occurring. As well, for those infants that may cross percentiles upward, the CDC curves of infants born at term provide a guide for a realistic expected size for age and what size is heavier than expected. An additional advantage from using the CDC data is that after 50 weeks of post menstrial age a transition can be made from the chart developed here to the CDC charts.

It has been suggested that the distribution of weights among fetuses that are born preterm may be smaller than those that remain in utero and are delivered at term [32], and therefore it may be better to use ultrasound data for measures of the size of infants that are not born prematurely. There are two reasons why it may be desirable to continue to use the size of preterm infants at birth as a growth reference. First, ultrasound data are variable and lack reproducibility [32-34]. As well, measurement of preterm infants provides weight, head circumference and length measurements while ultrasound only provides estimates of these measures.

The use of growth charts is only as accurate as the measurements that are made of the infants. Measurements of weight on electronic scales [35] and head circumference using paper tapes [36] have been shown to be reliable. However, measurement of length, even under controlled conditions on clinically stable infants is not very accurate or reliable and therefore growth may be undetected or appear excessive or inadequate [37]. To improve accuracy of length data, infants should be measured on a headboard by two people [38].

Unfortunately the literature that accompanied the population based data sources does not include a description of the scales and tapes used to measure the infants, nor of the accuracy of these instruments. Since the data sources were population based, it is likely that a variety of precision occurred.

Head growth is important to monitor, since growth that deviates from the intrauterine rate could indicate problems $[39,40]$. Calculation of growth velocity (gram $/ \mathrm{kg} /$ day over several days) is recommended since it is a precise measure of growth [38]. The most comprehensive growth assessment uses a calculation of growth velocity together with assessment of size relative to references for a given age on a growth chart.

At term age, infants born prematurely tend to have a different body composition than infants born at term, with lower weight, lean tissue and bone mineral content and a 
higher percent body fat [41]. The optimum body composition of the growing preterm infant is not known nor easily measured. Current growth charts provide no assessment of body composition.

\section{Conclusions}

This updated fetal-infant chart supports growth monitoring of preterm infants from as early as 22 weeks gestational age to 10 weeks post term age. It allows a comparison of an infant's growth with first the fetus and then the term infant and therefore allows an evaluation of catch up growth. Although Babson's "fetal-infant growth graph" had reasonably accurate estimates along the $50^{\text {th }}$ percentile, the larger sample sizes and more accurate gestational age assignments used here may provide better confidence in the extreme percentiles. As with all metaanalyses, the validity of this growth chart is affected by the methodological quality of the data sources and the heterogeneity of their results.

Comparison of the growth of the NICHD infants at attained weight of 2 kilograms provides evidence that, on average, preterm infants are growth retarded with respect to weight and length while, except for the smallest infants, their average head size has caught up to birth percentiles. Further validation work is needed to illustrate the growth patterns of preterm infants to older ages.

\section{List of Abbreviations}

kilogram (kg)

centimeter $(\mathrm{cm})$

\section{Center for Disease Control (CDC)}

National Institute of Child Health and Human Development Neonatal Research Network (NICHD)

\section{Competing interests}

None declared.

\section{Authors' contributions}

TF carried out the literature search, data selection, grid design, chart development, statistical comparisons and manuscript preparation.

\section{Acknowledgements}

Thanks to: Pat Fenton for assistance with the computer graph preparations, Doug McMillan for scientific and editorial advice, Debbie McNeil for statistical advice and Sari Czink and Suzanne Tough for editorial assistance.

\section{References}

I. Babson SG, Benda GI: Growth graphs for the clinical assessment of infants of varying gestational age. J Pediatr 1976, 89:8|4-820.
2. KF Catrine: Anthropometric Assessment. Nutritional Care for High Risk Newborns 3rdth edition. Edited by: Groh-Wargo S, Thompson $M$ and Hovasi-Cox J. Chicago, Precept Press; 2000.

3. DM Anderson: Nutrition for the low-birth-weight infant. Krause's Food,Nutrition and Diet Therapy 10thth edition. Edited by: Mahan LK and Escott-Stump S. Philadelphia, WB Saunders; 2000:23I.

4. Lubchenco LO, Hansman C, Boyd E: Intrauterine growth in length and head circumference as estimated from live births at gestational ages from 26 to 42 weeks. Pediatrics 1966, 37:403-408.

5. Dancis J, O'Connell JR, Holt LE: A grid for recording the weight of premature infants. J Pediatr 1948, 33:570-572.

6. Usher R, McLean F: Intrauterine growth of live-born Caucasian infants at sea level: standards obtained from measurements in 7 dimensions of infants born between 25 and 44 weeks of gestation. J Pediatr 1969, 74:901-910.

7. World Health Organization: Physical status: the use and interpretation of anthropometry. Report of a WHO Expert Committee. World Health Organ Tech Rep Ser 1995, 854: I-452.

8. Kramer MS, Platt RW, Wen SW, Joseph KS, Allen A, Abrahamowicz $M$, Blondel B, Breart G: A new and improved population-based Canadian reference for birth weight for gestational age. Pediatrics 200I, I08:E35.

9. Alexander GR, Himes JH, Kaufman RB, Mor J, Kogan M: A United States national reference for fetal growth. Obstet Gynecol I996, 87:163-168.

10. Arbuckle TE, Wilkins R, Sherman GJ: Birth weight percentiles by gestational age in Canada. Obstet Gynecol 1993, 81:39-48.

II. Niklasson A, Ericson A, Fryer JG, Karlberg J, Lawrence C, Karlberg P: An update of the Swedish reference standards for weight, length and head circumference at birth for given gestational age (1977-1 981). Acta Paediatr Scand 1991, 80:756-762.

12. Beeby PJ, Bhutap T, Taylor LK: New South Wales populationbased birthweight percentile charts. J Paediatr Child Health 1996, 32:5I2-518.

13. RJ Kuczmarski, CL Ogden, Grummer-Strawn LM et al: CDC growth charts: United States. Advance Data from vital and health statistics, no 3 I 4 Hyattsville, Maryland: National Center for Health Statistics. 2000; 2000.

14. Ogden CL, Kuczmarski RJ, Flegal KM, Mei Z, Guo S, Wei R, Grummer-Strawn LM, Curtin LR, Roche AF, Johnson CL: Centers for Disease Control and Prevention 2000 growth charts for the United States: improvements to the 1977 National Center for Health Statistics version. Pediatrics 2002, 109:45-60.

15. Kuczmarski RJ, Ogden CL, Guo SS, Grummer-Strawn LM, Flegal KM, Mei Z, Wei R, Curtin LR, Roche AF, Johnson CL: 2000 CDC Growth Charts for the United States: methods and development. Vital Health Stat I/ 2002:I-190.

16. Ehrenkranz RA, Younes N, Lemons JA, Fanaroff AA, Donovan EF, Wright LL, Katsikiotis V, Tyson JE, Oh W, Shankaran S, Bauer CR, Korones SB, Stoll BJ, Stevenson DK, Papile LA: Longitudinal growth of hospitalized very low birth weight infants. Pediatrics 1999, 104:280-289.

17. Niklasson A, Engstrom E, Hard AL, Wikland KA, Hellstrom A: Growth in very preterm children: a longitudinal study. Pediatr Res 2003, 54:899-905.

18. Wright K, Dawson JP, Fallis D, Vogt E, Lorch V: New postnatal growth grids for very low birth weight infants. Pediatrics 1993, 91:922-926.

19. Guo SS, Roche AF, Chumlea WC, Casey PH, Moore WM: Growth in weight, recumbent length, and head circumference for preterm low-birthweight infants during the first three years of life using gestation-adjusted ages. Early Hum Dev 1997, 47:305-325.

20. Committee on Nutrition American Academy of Pediatrics: Nutritional Needs of Preterm Infants. Pediatric Nutrition Handbook Elk Grove Village Il; 1998.

21. Nutrition Committee Canadian Paediatric Society: Nutrient needs and feeding of premature infants. CMAJ 1995, 152:1765-1785.

22. AF Roche: Executive Summary of the Low Birth Weight Workshop. US Department of Health and Social Services; Centers for Disease Control and Prevention; National Center for Health Statistics 1994.

23. Min SJ, Luke B, Gillespie B, Min L, Newman RB, Mauldin JG, Witter $F R$, Salman FA, O'sullivan MJ: Birth weight references for twins. Am J Obstet Gynecol 2000, I 82:1250-1 257. 
24. Kramer MS, Morin I, Yang H, Platt RW, Usher R, McNamara H, Joseph KS, Wen SW: Why are babies getting bigger? Temporal trends in fetal growth and its determinants. J Pediatr 2002, | 41:538-542.

25. Ananth CV, Wen SW: Trends in fetal growth among singleton gestations in the United States and Canada, 1985 through 1998. Semin Perinatol 2002, 26:260-267.

26. Fok TF, So HK, Wong E, Ng PC, Chang A, Lau J, Chow CB, Lee WH: Updated gestational age specific birth weight, crown-heel length, and head circumference of Chinese newborns. Arch Dis Child Fetal Neonatal Ed 2003, 88:F229-F236.

27. Fenton TR, McMillan DD, Sauve RS: Nutrition and growth analysis of very low birth weight infants. Pediatrics 1990, 86:378-383.

28. Hack M, Weissman B, Borawski-Clark E: Catch-up growth during childhood among very low-birth-weight children. Arch Pediatr Adolesc Med 1996, I 50: I I 22-I I 29.

29. B Rosner: Estimation. Fundamentals of Biostatistics 5thth edition. Pacific Grove, CA, Duxbury; 2000

30. Wang Z, Sauve RS: Assessment of postneonatal growth in VLBW infants: selection of growth references and age adjustment for prematurity. Can J Public Health 1998, 89: I09-I I 4.

31. Elliman AM, Bryan EM, Elliman AD, Harvey DR: Gestational age correction for height in preterm children to seven years of age. Acta Paediatr 1992, 81:836-839.

32. Bukowski R, Gahn D, Denning J, Saade G: Impairment of growth in fetuses destined to deliver preterm. Am J Obstet Gynecol 200I, 185:463-467.

33. Mongelli $M$, Biswas $A$ : Menstrual age-dependent systematic error in sonographic fetal weight estimation: a mathematical model. J Clin Ultrasound 2002, 30: I39-144.

34. Chauhan SP, Charania SF, McLaren RA, Devoe LD, Ross EL, Hendrix NW, Morrison JC: Ultrasonographic estimate of birth weight at 24 to 34 weeks: a multicenter study. Am J Obstet Gynecol I998, 179:909-916.

35. Engstrom JL, Kavanaugh K, Meier PP, Boles E, Hernandez J, Wheeler $D$, Chuffo R: Reliability of in-bed weighing procedures for critically ill infants. Neonatal Netw 1995, 14:27-33.

36. Sutter K, Engstrom JL, Johnson TS, Kavanaugh K, Ifft DL: Reliability of head circumference measurements in preterm infants. Pediatr Nurs 1997, 23:485-490.

37. Rosenberg SN, Verzo B, Engstrom JL, Kavanaugh K, Meier PP: Reliability of length measurements for preterm infants. Neonatal Netw 1992, I I:23-27.

38. Fomon SJ Nelson SE.: Size and growth. Fomon SJ.Nutrition of Normal Infants. St Louis, Mosby; 1993:49.

39. Hack M, Breslau N, Weissman B, Aram D, Klein N, Borawski E: Effect of very low birth weight and subnormal head size on cognitive abilities at school age. N Engl J Med I99I, 325:23I-237.

40. Georgieff MK, Hoffman JS, Pereira GR, Bernbaum J, Hoffman-Williamson M: Effect of neonatal caloric deprivation on head growth and I-year developmental status in preterm infants. J Pediatr 1985, 107:581-587.

41. Atkinson SA, Randall-Simpson J: Factors influencing body composition of premature infants at term-adjusted age. Ann NY Acad Sci 2000, 904:393-399.

\section{Pre-publication history}

The pre-publication history for this paper can be accessed here:

http://www.biomedcentral.com/1471-2431/3/13/prepub
Publish with Biomed Central and every scientist can read your work free of charge

"BioMed Central will be the most significant development for disseminating the results of biomedical research in our lifetime. "

Sir Paul Nurse, Cancer Research UK

Your research papers will be:

- available free of charge to the entire biomedical community

- peer reviewed and published immediately upon acceptance

- cited in PubMed and archived on PubMed Central

- yours - you keep the copyright
BioMedcentral 